\title{
Erratum and author correction
}

Flume PA, Aitkin ML, Bilton D, et al. Optimising inhaled mannitol for cystic fibrosis in an adult population. Breathe 2015; 11: 39-48. DOI: 10.1183/20734735.021414.

Regrettably, there was an error in figure 3 of the article mentioned above. The correct figure is presented below. We apologise to the readers of Breathe for this error.

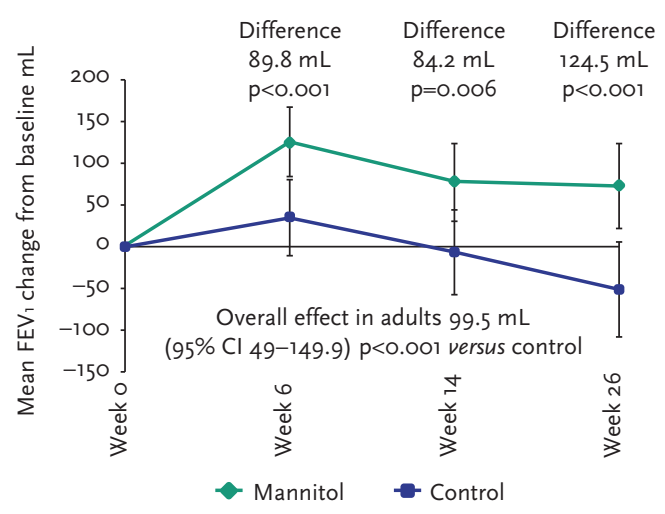

Jacinto T, Boots A, Bikar A, et al. Doing Science: Oral presentations. Breathe 2014; 10: 79-81. DOI: 10.1183/20734735.101214.

The authors regret that two authors were omitted from the manuscript. The correct author list is as follows:

Tiago Jacinto, Agnes Boots, Andres Bikar, Georgia Hardavella, Neil Saad and Anders Bjerg. 